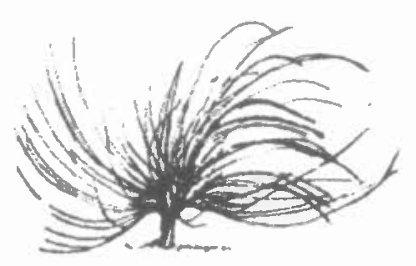

\title{
La (re)construcción de las identidades en la música popular andina en Perú: un campo de disputa y negociación cultural
}

\author{
Fanny Pineau ${ }^{l}$ \\ Universidad La Soborna-París \\ París \\ fafoline@yahoo.fr \\ Andrés Mora Ramírez ${ }^{2}$ \\ Universidad Nacional, Costa Rica \\ Heredia, Costa Rica \\ agmora@gmail.com
}

\begin{abstract}
Resumen
Este ensayo analiza la construcción y transformación de las identidades culturales en el Perú: un proceso complejo, multidimensional, conflictivo y dinámico, en el que intervienen referentes locales, nacionales y globales, políticos e históricos, que involucran a sujetos individuales y colectivos en disputa por la hegemonía. El caso de la música popular andina, que se desarrolla en el texto, es uno de los ámbitos que ofrecen mayores y más ricos elementos en el estudio de las identidades culturales.
\end{abstract}

Palabras claves: Identidades culturales, multidimensional, referentes locales, nacionales, hegemonía, música popular andina, transformaciones demográficas, dominantes, dominados.

Recibido: 08 de setiembre, 2010 - Aprobado: 29 de junio, 2011

Magister en Estudios Latinoamericanos. Por IHEAL - Université La Sorbonne Nouvelle

Magister en Estudios Latinoamericanos. Por la Universidad Nacional de Costa Rica. 


\begin{abstract}
This paper analyzes the construction and transformation of the cultural identities in Peru: a complex, multidimensional, conflicting, and dynamic process in which local, national, global, political, and historical referents that involve individual and collective subjects fight for hegemony. The Andes regional folk music is one of the scenarios that offer the biggest and richest elements in cultural identity studies.
\end{abstract}

Keywords: Cultural identities, multidimensional, local and national referents, hegemony, Andes folk music, demographic transformations, dominant and dominating subjects.

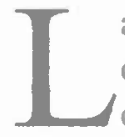

a construcción y permanente reelaboración de las identidades culturales constituye un proceso complejo, multidimensional, conflictivo y dinámico, en el que intervienen referentes locales, nacionales y globales, políticos e históricos, que involucran a sujetos individuales y colectivos en disputa por la hegemonia. En el caso del Perú, uno de los ámbitos que ofrecen mayores y más ricos elementos para el estudio de las identidades es el de la música popular andina, siendo éste "un vasto territorio en el que se expresan sensibilidades, gustos, preferencias, modos de ver el mundo y sentir" (Ibarra, 2004).

En efecto, en los últimos 50 años la música popular andina ha experimentado un proceso de modernización que, paralelo a las grandes transformaciones demográficas de la sociedad peruana, producto de las migraciones internas y de la crisis política y económica, expresa la conformación de un campo de fuerzas - un campo cultural, según la tesis de Bourdieu- en el que los dominantes y los dominados se involucran, en el marco de sus relaciones sociales, en una lucha por la disposición y la hegemonía de los llamados capitales simbólicos (Ibarra, 2004; y Santillán y Ramírez, 2004).

Una de los principales escenarios de esta disputa remite, precisamente, a la evolución de la música popular y el desarrollo de las industrias culturales en el Perú. No en vano, José María Arguedas escribió en 1977 que "los instrumentos más eficaces por medio de los cuales se intenta condicionar la mentalidad de las masas y desarraigarlas de su tradición singularizante, nacionalista (la radio, la TV), se convierten en 
vehículos poderosos de transmisión de lo típico, de lo incolonizable” (Alfaro, 2005).

En razón de lo anterior, en este ensayo nos interesa analizar la manera en que estos elementos, a saber, los procesos migratorios, el desarrollo y difusión masiva de géneros musicales como el huayno, la chicha y la tecnocumbia, y la presencia creciente de las industrias culturales, influyen en la (re)construcción de las identidades culturales peruanas, y en las nuevas formas de resistencia y persistencia de las culturas populares y andinas en nuestros días.

Las migraciones internas en el Perú: factor clave de la reelaboración de las identidades culturales.

Las identidades culturales en el Peru se han transformado a través de la historia en diferentes contextos políticos y socioeconómicos. Las migraciones desde el campo a la ciudad, o más concretamente en la realidad geográfica peruana, desde la sierra a la costa, representan un factor clave en la reelaboración de las identidades culturales y en la eclosión de la música popular andina a escala nacional.

El Perú, como país multiétnico y de gran heterogeneidad cultural, se enfrentó a numerosos desafíos a la hora de crear una identidad cultural nacional, siendo la occidentalización de la sociedad el recurso más utilizado para alcanzar este fin. Contrariamente a otros paises latinoamericanos, aquí la industrialización, truncada posiblemente por la inestabilidad política, ha sido mínima en los procesos de modemización de la sociedad; sin embargo, esto no impidió migraciones masivas hacia la costa, principalmente hacia la capital Lima, pero también hacia ciudades como Trujillo o Arequipa.

La centralización del poder político, económico y cultural en Lima, además de la crisis agraria presente en el resto del territorio y la creciente polarización entre campesinos y terratenientes (avance de las relaciones mercantiles) dieron lugar a intensos flujos migratorios desde los años cuarenta.

Los indigenismos, primero, y luego los movimientos campesinos, expresaron el descontento frente a las relaciones de poder establecidas en la sociedad peruana inmersa en el sistema capitalista. Solamente el gobierno militar de Velasco Alvarado (1968-1975), con un tinte de populismo, escuchó las demandas populares y emprendió una reforma 
agraria así como la creación del Festival Inkarrí y la promoción del arte popular. Paralelamente, seguían las migraciones hacia la costa, donde se buscaba mano de obra barata y donde la oportunidad de trabajo significaba mejor calidad de vida y acceso a servicios de salud y educación.

Cabe notar que además de esta migración tradicional, se han dado en Perú migraciones forzadas, desplazamientos por violencia política debidos a la guerra sucia (1980-1992), los enfrentamientos entre el grupo de inspiración maoísta Sendero Luminoso y las Fuerzas Armadas. Estos largos años de crisis generalizada favorecieron las migraciones, los sentimientos de desprecio y temor en la sociedad limeña y una crisis de la identidad urbana.

En efecto, ocurre en el proceso de migración una desterritorialización de las identidades culturales que se reelaboran luego en un ambiente urbano con nuevas interrelaciones, nuevas actividades y condiciones de vida. La crisis de la identidad urbana, a partir de las migraciones, revela el escenario de enfrentamientos entre las contradicciones maniqueas evocadas en las ciencias sociales: campo/ciudad; tradición/ modernidad; popular/culto.

Como lo plantea Martín Barbero, ha habido un "destiempo entre Estado y Nación" (Barbero; 1987) en la modernización de las instituciones, infraestructuras, relaciones comerciales, por parte del Estado y su centralización en la capital que generó mayor desfase entre campo y ciudad. El campo se volvió mundo paralelo al de la ciudad, donde subsiste lo tradicional, también visto como premoderno y arcaico pero donde se guarda la cosmovisión heredada de sus ancestros y éstas se materializan en costumbres, fiestas, rituales ${ }^{3}$.

La oposición entre lo popular y lo culto refleja las disimilitudes culturales generadas por el conflicto entre tradición y modernidad, es decir, la manera de ser, actuar y pensar en el mundo que se habita. Mientras lo popular califica las formas no contaminadas ${ }^{4}$ de relacionarse con los otros, de expresarse culturalmente (persistencia de la oralidad), lo culto tiene el mérito de ser legitimado por la relación moderna

3 Esta posición ha sido controvertida principalmente frente a los procesos de globalización que alcanzarían al mundo entero de la misma forma y entonces llevaría a la desaparición de las fronteras entre campo y ciudad, cosa que en la realidad no es tan evidente.

4 Veremos posteriormente que para una definición rigurosa de lo popular habría que dar cuenta de las diferentes formas que ha tomado lo popular en su relación con lo folclórico y la tradición así como en la occidentalización y mercantilización de lo popular. 
entre saber y poder que le da relevancia e importancia por ser refinado, distinguido y portador de la verdad.

De este modo, la nación se fragmenta entre hegemonía y subalternidad, entre una fuerza dominante que se impone en la sociedad y tiende a atraer por su relación con el poder, mientras que lo subalterno revela una condición subordinada, aniquilada, que genera lucha y resistencia contra una fuerza opresora. Pajuelo (2002) subraya que esta contradicción viene de la teoría de la dependencia: existe una dependencia cultural generada por la dominación ejercida sobre la capacidad creativa y la elaboración cultural de los grupos sociales dominados.

Sin embargo, cabe añadir que el maniqueísmo de estas oposiciones se refleja con más matices en la realidad. Los nuevos limeños provincianos viven entre tradición y modernidad, adoptan diferentes comportamientos en función de las situaciones. Recrean comunidades imaginadas en su nuevo entorno, buscan las relaciones de parentesco o compadrazgo, celebran fiestas populares o patronales de sus provincias, hablan en lenguas vernáculas y solamente en presencia de una persona extraña usan el castellano. Juntos van a clubes de provincianos, comedores populares, organizaciones de apoyo e inserción en la sociedad que les explican como aparentar, como interactuar y hablar en la sociedad moderna y occidental, pero paralelamente subsisten raíces culturales que, en la recreación de una colectividad y en la reelaboración de identidades culturales, adquieren un nuevo sentido en la ciudad.

\section{Desarrollo y fusión de nuevos géneros musicales: el ejercicio de la resistencia y la persistencia cultural.}

En estos procesos de reelaboración identitaria que tienen lugar en Lima, en el contexto de una crisis política y económica que se prolonga en el tiempo (inicia alrededor de los años 1950 y se extiende hasta finales del siglo XX y principios del XXI), la música popular, en la que ubicamos la llamada música andina o folclórica y los géneros de fusión, desempeña un papel crucial como medio de expresión y construcción de nuevas identidades culturales así como para el ejercicio de la resistencia y la persistencia cultural. En este sentido, Roel Mendizábal (2000) considera que:

"la creación musical andina, antes anónima y local, ha pasado a tener autor y a ser masiva y ampliamente difundida, más allá de las 
fronteras regionales y étnicas: esto es, ha pasado de ser folklórica (...) a ser popular (...), mostrando por cierto gran adaptabilidad a los vaivenes de la industria musical. Esta nueva realidad se considera producto de un proceso de integración y urbanización".

Precisamente, en las transformaciones y creaciones de la música popular, en especial a partir de la segunda mitad del siglo XX, es posible observar el posicionamiento de fuerzas en competencia en un campo cultural: por un lado, las clases hegemónicas adoptaban e imponian el vals criollo como el género musical nacional, integrador de las experiencias de lo peruano, pero cuyas composiciones, dirigidas por y hacia las clases media y alta (finalmente, el público consumidor), reproducían la visión de la oligarquía limeña y, por lo tanto, idealizaban un Perú que no existía (León, 2005). Pero frente a esto, los migrantes andinos y los grupos marginados de la identidad nacional, los actores y sujetos sociales que no poseían carta de ciudadanía en ese Perú imaginado, reconfiguran sus manifestaciones culturales, sus espacios de convivencia social y de expresión musical en las nuevas condiciones de vida en la ciudad, y desde allí, mediante la producción musical, cuestionan, socavan y disputan la hegemonía cultural construida por la élites.

En este sentido, nos interesa destacar aquí la evolución de tres géneros en los cuales es posible observar el fenómeno de lo que MartínBarbero (1987) denomina como "lo popular que nos interpela desde lo masivo", y donde se realiza el ejercicio de la resistencia y la persistencia cultural, por parte de los nuevos limeños.

Nos referimos al huayno, la canción andina por excelencia y a la que Arguedas (citado por Alfaro, 2005) definía como la "voz y expresión más legítima del Perú indio y mestizo a través de todos los tiempos"; la chicha ${ }^{5}$ que se inspira en el huayno combina la música tropical con el rock ; y finalmente la tecnocumbia, surgida de la fusión entre la cumbia colombiana y el tecno, y que privilegia el uso de instrumentos electrónicos y ritmos secuenciados a partir del sintetizador, la tumba y la batería electrónica (Santillán y Ramírez, 2004).

En un período de más de cincuenta años (de 1953 a la fecha), y paralelo a los cambios demográficos que acontecían en la capital, el huayno experimentó su propia metamorfosis cultural, abandonando su

5 La chicha originalmente es una bebida prehispánica elaborada a base maíz, de ahí su vínculo con la tierra madre y las poblaciones autóctonas. La música chicha, en consecuencia, refleja este vínculo con lo andino. 
aparente reclusorio -y quizá destierro por parte de las élites- en las comunidades indigenas de la región andina del centro y sur del Perú, para extenderse por todo el país en razón de los movimientos migratorios, e incluso para conquistar los medios de comunicación y la industria fonográfica y audiovisual (los modernos vehículos de difusión cultural).

Lima, entonces, se convirtió en una suerte de plataforma de lanzamiento o proyección donde el huayno hizo visibles a los indígenas quechuas y sus problemáticas específicas en los contextos urbanos. Pero más importante aún, abrió nuevos canales de rescate y difusión de las culturas populares y andinas, de sus dimensiones todavía incolonizables ${ }^{6}$.

García Miranda (1993) sostiene que el huayno debe entenderse "como una forma de tradición oral, a través de la cual el poblador andino expresa y transmite una diversidad de manifestaciones culturales, entre ellas su ideología, costumbres, formas de comportamiento, cosmogonía, valores ético-morales así como sus diversos logros y frustraciones en la vida diaria". Recordemos también que en el contexto de la guerra interna del Perú, los huaynos tendieron a hacerse clandestinos, su difusión se restringió al haber sido catalogados como propaganda de los grupos alzados contra el poder. Para ilustrar el profundo sentido de este género, que consideramos como canto al dolor, la miseria y la violencia, El Hombre (de 1970, compuesto por Justo Pastor Chirinos Alarcón) encarna uno de los huaynos más representativos del Perú7, tres de sus estribillos dicen:

Yo no quiero ser el hombre que se ahoga en su llanto de rodillas hechas llagas que se postra al tirano.
Yo quiero ser el hermano que da mano al caído y abrazados férreamente vencer mundos enemigos.

\section{Para qué vivir de engaños cholita de palabras que segregan veneno acciones que martirizan al mundo}

- En esta tarea se destaca el impulso que José María Arguedas dio, desde el Ministerio de Educación y su propio trabajo intelectual, a la promoción del huayno y al uso del mercado para salvar "la avasallada cultura andina", inspirado en lo que entendía como el deber de estrechar "el círculo de los hombres que alimentan viva la oscura tradición del menosprecio a la música india" (Alfaro, 2005).

7 Véase el anexo 1 que proporciona este texto en su integridad así como otros huaynos particularmente ilustrativos. 
Ay sólo por tus caprichos dinero

Ay sólo por tus caprichos riqueza.

Una clara manifestación de lo anterior se observa en el Festival Ayacuchano que se celebra anualmente en Lima, durante los meses de febrero y marzo, y que logra convocar a más de 200 mil personas. Con el huayno como eje articulador, las filiales campesinas, clubes culturales y asociaciones integradas por migrantes de Ayacucho, se apropian de los espacios de la ciudad para ejercer su "derecho a desarrollar la propia cultura en espacio públicos apropiados" y para hacer "sentir su presencia ante los ojos de los demás, inclusive ante las autoridades del gobierno central y regional" (Vázquez, 2007), en definitiva, para revitalizar el cuerpo social, la identidad y reproducir la memoria cultural de los pueblos andinos.

Con un origen mucho más urbano, específicamente de los suburbios de Lima, la cumbia peruana o chicha surgió hacia finales de la década de 1960, cuando algunos grupos mezclaron la música tropical con el rock, llamando así la atención del público inmigrante provinciano en la capital y, a la vez, despertando su melancolía. Pero no fue sino hasta la década de 1980 que se produjo el auge de nuevos grupos de este género. Uno de los grupos chicheros ${ }^{8}$ particularmente reconocidos en Lima son Los Shapis, quienes en canciones como Mi tallercito o Ambulante soy (1986), transcriben eventuales dificultades diarias de los provincianos en Lima:

\section{Ambulante soy, proletario soy}

Vendiendo zapatos, vendiendo comida, vendiendo casacas

Mantengo mi hogar

Ay ay ay qué triste es vivir, qué triste es soñar.

También, cabe destacar a Juan Tongo, quien en su famosa canción $L a$ Pituca $^{9}$ toca un tema tabú de la sociedad peruana, a saber, las relaciones amorosas entre blancos y cholos:

Véase el anexo 2 que ofrece letras de diferentes autores ilustrativos de la música chicha en Perú.

9 El término pituco(a), en el Perú, alude a las personas adineradas. Además, no se puede concebir un pituco cholo : existe paralelamente una relación implícita entre clase social y origen étnico ya que un pituco tiene que ser blanco. 
Porque pituca me quieres a mi

Si yo soy un chichero nomás

(...) En el amor no hay barreras

No existen los defectos, no existe el color

(...) En el amor no hay clase social.

Además, Chacalón y su hijo Chacalón junior representan el camino que la música popular andina ha tomado a lo largo de los años: el padre como precursor de la chicha y el hijo maestro de la tecnocumbia. Chacalón ha tenido un gran éxito que marcó las fiestas populares limeñas con la canción Soy provinciano:

Soy muchacho provinciano

me levanto muy temprano

para ir con mis hermanos

ayayay a trabajar.

(...) Sólo tengo la esperanza

ayayay de progresar

busco un nuevo camino en esta ciudad

donde todo es dinero y hay maldad.

En la chicha confluyen distintas corrientes musicales y culturales, como el huayno, la cumbia colombiana y los ritmos caribeños de Cuba. Los músicos, compositores y público de este género, conocidos como chicheros, provienen de los sectores populares de la capital, con un predominio de los migrantes de la sierra y la selva peruana. De ahí que durante mucho tiempo, y como parte de esa definición hegemónica de lo peruano en la música -la dicotomía de lo culto y lo popular-, las letras, la estética (que incorporaba elementos del folclor de la sierra) y los espectáculos de los chicheros (en los llamados chichódromos), fueron estigmatizados por las élites peruanas.

En una lectura de esta situación desde la perspectiva del campo cultural, la reacción de la oligarquía se explica por cuanto a través de la chicha los sectores populares realizaban, de manera más o menos consciente, "la sintesis de un nuevo limeño" (especialmente en la década de 1970): "un serrano acriollado que hace una imitación grotesca de la vestimenta occidental", lo que para algunos representaba un 
"intento desesperado de adaptación, para posteriormente constituirse en una marca de diferencia" (Bailón, 2004).

No en vano Degregori (1984, citado por Gargurevich, 2000) sostiene que la música chicha guarda estrecha relación con las nuevas presencias andinas en Lima, y con la capacidad de este fenómeno de la cultura musical de permitir "la cohesión grupal de esa inmensa masa de migrantes andinos, articulados cada vez más estrechamente a aquellos que no migraron, o regresaron, o se aprestan recién a migrar" y capaz de desplazar, incluso, al vals criollo de su lugar de privilegio en la definición de la identidad nacional.

Estrechamente ligado al desarrollo de la chicha o cumbia peruana, en la década de 1990 aparece la tecnocumbia, una suerte de movimiento musical modernizador con gran acogida entre los jóvenes y amplios sectores de la sociedad peruana ${ }^{10}$, incluidos públicos de clase media y alta. Sin embargo, a diferencia de la singularidad buscada y expresada por medio del huayno y la chicha, en la tecnocumbia se advierte una influencia explicita de elementos de la cultura de masas norteamericana (por ejemplo, con una estética de los artistas inspirada, claramente, en los productos culturales de la cadena mexicana Televisa).

Este género musical es esencialmente un producto hecho para la venta, cuyos textos remiten fundamentalmente a las relaciones amorosas, falta en las letras un contenido social o cultural que interpele directamente a las poblaciones populares y/o andinas. ¿Se trataría, entonces, de un género superficial y de moda? Dada la novedad del fenómeno de la tecnocumbia, seria prematuro pronunciarse sobre su lugar en el campo cultural de la música peruana, sea del lado de la oligarquía, sea del lado de los sectores populares.

Ciertamente, se le reconoce su capacidad para propiciar un proceso de identificación con ídolos populares y hasta el surgimiento de "una noción de música nacional popular", que promueve una "adhesión de tipo nacional en circunstancias de fuertes migraciones de tipo internacional" (Ibarra, 2004) como las que experimenta Perú y el conjunto de la región andina. Además, Mejía Navarrete (2007) considera que el éxito alcanzado por este género se debe a que logró articular un discurso musical "multiclasista, multiétnico, pannacional e internacional".

10 Cabe destacar el uso de este género musical en los spots publicitarios por parte de Alberto Fujimori, en su campaña electoral por la Presidencia de la República. 
Sin embargo, esta potencia aglutinadora de la tecnocumbia no emerge de ni se orienta hacia un proyecto cultural y social emancipatorio, sino que su tránsito en la esfera de lo popular parece tender por ahora, de manera privilegiada, a las rutas del mercado y la cultura global. En este sentido, podría decirse que se trata de un género ambiguo, que evidencia las tensiones y contradicciones existentes entre la creación artística popular y las demandas de las industrias culturales, en el escenario de la globalización neoliberal.

\section{Las industrias culturales en la modernización de la música popular andina.}

La fusión musical en el Perú revela la existencia de nuevas identidades y de culturas populares a caballo entre el rescate y preservación de lo tradicional y la inmersión en la modernidad. Esta modernización de la música popular andina ha sido impulsada, fundamentalmente, por las industrias culturales ${ }^{11}$; No obstante, el movimiento sociocultural que acompaña y constituye a cada género mantiene distintos tipos de relaciones con el aparato de producción y comercialización de bienes, lo que responde, también, a concepciones diferentes sobre la construcción de la identidad y la memoria colectiva.

Así, el huayno, más cercano a la tradición indígena, ha logrado desarrollar una importante industria cultural autóctona, independiente, sostenida por medio de redes étnicas y populares, que operan al margen de los poderes hegemónicos locales y globales. A diferencia del funcionamiento de los circuitos comerciales, que enfatizan en la producción de discos, vídeos y otros objetos de consumo, estas nuevas industrias culturales tienen como objetivo principal la organización de espectáculos, la congregación de las personas y la constitución de espacios sociales de intercambio simbólico.

En este proceso, proveen a la población migrante, usualmente considerada solo como consumidora -cuando no como un obstáculo que debe eliminarse-, los insumos y lugares necesarios para (re)construir

"Seguimos aquí la definición de industrias culturales que propone UNESCO, a saber, aquellas que conforman "sectores que conjugan creación, producción y comercialización de bienes y servicios basados en contenidos intangibles de carácter cultural, generalmente protegidos por derechos de autor" (UNESCO. 2000. Study on International Flows of Cultural Goods, 198098. París: UNESCO). 
identidades y deliberar sobre sus problemas, para "representarse a sí mismos, moldear cuerpos y conductas, imaginarse comunidades y narrar experiencias sentimentales en su propio vocabulario (...). En suma: hacer circular cultura masiva hecha por y para el pueblo" (Alfaro, 2005).

En cambio, la chicha y la tecnocumbia, quizá por su origen urbano y sus numerosas influencias, tanto locales como transnacionales, parecen estar sujetas a una relación de mayor dependencia de las industrias culturales globales, de las demandas y la lógica misma del mercado (es decir, ligadas al capitalismo de consumo).

Al respecto, se han formulado, al menos, dos explicaciones. Una de ellas señala que el auge de estos dos géneros, en coincidencia con el desborde popular del proceso de ciudadanización de los nuevos limeños, representó una suerte de "descubrimiento del universo migrante y la mercantilización de la producción artesanal y musical" (Roel Mendizábal, 2000).

La otra explicación pone su acento en una característica casi constitutiva de la chicha y la tecnocumbia: su desarrollo e innovación a partir de las influencias de una estética moderna, globalizada, lo que habría dado paso a la incorporación de elementos (sonoros, estéticos, productivos) que han tenido aceptación y éxito en otros mercados. Esto se aprecia, por ejemplo, en el reciclaje de canciones "que originalmente fueron compuestas como baladas, tonadas, albazos, huaynos, sanjuanitos" (Santillán y Ramírez, 2004).

No obstante tales diferencias, resulta evidente que el huayno, la chicha y la tecnocumbia abrieron y consolidaron espacios de expresión de la cultura popular en la estructura de los medios de comunicación masivos, y en consecuencia, los sectores de población que se miran y expresan en estos movimientos musicales, y que los asumieron como parte de sus (re)elaboraciones identitarias, han reconfigurado sus posiciones en el campo cultural de la sociedad peruana.

De esta manera, en el contexto cultural del Perú, los festivales populares, los conciertos, los chichódromos, los medios de comunicación y las industrias culturales (las autóctonas y las globales), se convierten en "foros públicos en los que diferentes modelos sociales son afirmados, desmentidos, negociados y adoptados (...) a través del vínculo entre las prácticas de su vida cotidiana y los formatos de mediación 
masiva", donde convergen y se problematizan las relaciones entre flujos simbólicos nacionales y transnacionales (Alfaro, 2005).

\section{¿Hibridación o negociación y disputa cultural?}

García Canclini (1996) habla de hibridación de las culturas en el contexto de la globalización, donde los medios de comunicación, las industrias culturales y la ideología del consumo inducen a los ciudadanos a convertirse en consumidores de bienes homogeneizantes. La cultura, desde su punto de vista, se convierte así en "un proceso de ensamblado multinacional, una articulación flexible de partes, un montaje de rasgos que cualquier ciudadano de cualquier país, religión e ideología puede leer y usar".

Efectivamente, el consumo tiende a homogeneizar, pero preferimos pensar que las culturas no se transforman en hibridas, como una suerte de destino inexorable, sino que en función de las dinámicas sociales, políticas e históricas, y hasta de la intensidad de la dominación y sus oposiciones, las culturas evolucionan, adoptan, negocian y asumen ciertos comportamientos y referentes simbólicos. No se trata, entonces, de una mezcla de influencias constantemente presente en los sujetos individuales y colectivos, sino de una apropiación, en momentos definidos, de maneras de ser e interactuar originales, que corresponden a una cosmovisión tradicional y en otros momentos la apropiación de nuevas formas de ser e interactuar que han sido asimiladas en un nuevo entorno, por ejemplo en la ciudad moderna.

Desde nuestra perspectiva, la aceptación de la hibridación cultural per se entraña el peligro de creer que se van disolviendo las fronteras entre la cultura popular y la cultura de élite, cuando resulta evidente que las confrontaciones abiertas y los prejuicios sociales siguen vigentes en las sociedades latinoamericanas y, particularmente, en la peruana.

Es por esto que consideramos más apropiada la noción de campo cultural para el análisis de la (re)construcción de las identidades y la música popular andina en el Perú, toda vez que permite abordar la naturaleza y matices de la producción artística, así como de las relaciones de poder y la negociación cultural entre lo hegemónico y lo popular, en un campo "que tiene sus propios valores, estéticas, lógicas de funcionamiento y formas de representar las condiciones de vida de sus públicos" (Santillana y Ramírez, 2004). 
Consecuentemente, destacamos la importancia adquirida por los géneros de fusión, fruto de una rica e intensa actividad de las culturas populares andinas, para generar una nueva narrativa social: "la de los que decidieron migrar a la capital y han impuesto allí las costumbres de su pueblo" y que, en determinados escenarios y coyunturas, enfatiza la dimensión étnica y en otros la pertenencia a una clase (popular) para la (re)construcción de las identidades. Se trata, pues, de un nosotros que "cubre prácticamente a todos los peruanos, menos a la élite llamada por algunos como criolla, ya que incluye a los provincianos residentes en Lima y en el interior del país. (...) Lo particular es que en estas narrativas los provincianos no aparecen como los humildes vencidos sino como gloriosos conquistadores" (Alfaro, 2005), que vencieron la pobreza y las adversidades de la ciudad.

De esta forma, serranos, provincianos, cholos, chicheros, los migrantes y sus hijos e hijas que crecen en la cultura de la tecnocumbia, encuentran en esta narrativa musical un modo de alcanzar visibilidad, presencia y reconocimiento para incluir lo andino y lo popular-aunque con evidentes contradicciones y conflictos- en la construcción simbólica del Perú, en un momento particularmente complejo de apertura y transnacionalización de los referentes culturales.

Sin embargo, este avance cultural y popular tiene un enorme desafio pendiente: el de cuestionar, efectivamente, el poder político y modificar las jerarquías sociales más rancias, no sólo en el plano simbólico, sino también en la línea de promover y exigir reformas estructurales, que profundicen la democracia y realicen la justicia social, para evitar, como dice Alfaro (2005), que el slogan del triunfo del provinciano en la ciudad no sea solo un espejismo o "un bálsamo para el excluido". 


\section{REFERENCIAS}

Alfaro Rotondo, Santiago (2005). Las industrias culturales e identidades étnicas del huayno. En: Pinilla, Carmen María (Ed.). Arguedas y el Perú de hoy. Lima: SUR.

Bailón, Jaime (2004). La chicha no muere ni se destruye, sólo se transforma. En Iconos. Revista de Ciencias Sociales. Enero, $n^{\circ} 18$. Facultad Latinoamericana de Ciencias Sociales, Sede Académica de Quito, Ecuador. Pp. 53-62.

Garcia Canclini, Nestor (1996). Culturas hibridas. Estrategias para entrar y salir de la modernidad. Argentina: Editorial Sudamericana.

Garcia Miranda, Julio (1993). Historia e identidad en el wayno ayacuchano. En Perí contemporáneo. El espejo de las identidades, Melgar Bao, Ricardo (compil). México DF: UNAM.

Gargurevich, Juan (2002). Bailanta y Chichódromo, algunas respuestas a la gran industria cultural del Norte. Pontificia Universidad Católica del Peri, recuperado en: http://www.pucp.edu.pe/departamento/comunicaciones/images/documentos/comunica_memoria_2007.pdf

Ibarra, Hernán (2004). La construcción social y cultural de la música. En Iconos. Revista de Ciencias Sociales. Enero, $\mathrm{n}^{\circ}$ 19. Facultad Latinoamericana de Ciencias Sociales, Sede Académica de Quito, Ecuador. pp. 80-86.

León, Javier (2005). Ni inga ni mandinga: reflexiones sobre el nacionalismo criollo y la música popular en Lima. Ponencia presentada al VI Congreso Latinoamericano de la Asociación Internacional para el Estudio de la Música Popular Latinoamericana. Buenos Aires. Recuperado en: http://www.hist.puc.cl/iaspm/baires/ articulos/javierleon.pdf

Martín Barbero, Jesús (1987). De los medios a las mediaciones. Cultura, hegemonia y poder. Convenio Andrés Bello, Bogotá. Pp. 317-333

Mejía Navarrete, Julio (2007). Globalización y cultura. Dimensiones peruanas. En Investigaciones Sociales, año XI, $\mathrm{n}^{\circ} 18$. Universidad Nacional Mayor de San Marcos, Lima. Pp. 345-358.

Pajuelo Teves, Ramón (2002). El lugar de la utopia. Aportes de Anibal Quijano sobre cultura y poder. En Daniel Mato (coord.), Estudios y Otras Prácticas. Intelectuales Latinoamericanos en Cultura y Poder. Caracas: CLACSO. Pp. 225-234.

Roel Mendizábal, Pedro (2000). De folklore a Cultura Hibridas: rescatando raíces, redefiniendo fronteras entre nos/otros. En No hay país más diverso. Compendio de antropología peruana, Degregori (ed), Lima: Red para el Desarrollo de las Ciencias Sociales en el Perú.

Santillán, Alfredo y Ramírez, Jacques (2004). Consumos culturales urbanos: el caso de la tecnocumbia en Quito. En Iconos. Revista de Ciencias Sociales. Enero, $\mathrm{n}^{\circ}$ 18. Facultad Latinoamericana de Ciencias Sociales, Sede Académica de Quito, Ecuador. Pp. 43-52.

Vásquez, Chalena (2007). Carnaval ayacuchano en Lima: De la Comunidad Campesina al Estadio Nacional. En: Conclusiones del III Congreso de Arte, Lima. Recuperado en: http://www.trioloscholos.com/estudios.html9 